\title{
WARGAMING AS A FORM OF HISTORICAL SIMULATION
}

\author{
Artem I. Kharinin \\ Volgograd State University, Volgograd, Russian Federation \\ Larisa V. Kharinina \\ Volgograd State University, Volgograd, Russian Federation
}

\begin{abstract}
Introduction. Wargames are an ancient invention of humankind. A new type of wargames was made in the $19^{\text {th }}$ century. Further it went through the evolution from a military application to historical simulation that can be used as a mathematical model in researching some issues of historical science. Methods. The authors base the research on the tradition of "cliometry" and "quantitative history", which apply the following methods: variative analysis, method of average, and statistical analysis. Analysis. The paper presents the describtion of the main stages of wargames' evolution and their influence on military arts and historical science. The authors consider the most important transformations: from entertaining board games to practical military guides and further to applied historical studies. The article describes the principals of creating such games and the influence of science subject area on their rules. The paper shows the boundaries of application of this method. The authors highlight advantages and disadvantages of game simulation and its practical potential as an auxiliary historical discipline. The paper also provides short analyses of the main monographs. The authors give examples of wargames that have played an important role in the development of game simulation, describe the main contemporary types of wargames, and give the criteria of historical accuracy and analytical potential. Results. Modern wargames allow us to make any military historical research more impersonal and measured. The researcher can adjust the rules more flexibly and determine the science subject borders. American researchers outlined the main principles of self-creating wargames for testing some hypothesis suggested by historians.
\end{abstract}

Key words: wargame, historical simulation, unit, zone of control, game scale.

Citation. Kharinin A.I., Kharinina L.V. Wargaming as a Form of Historical Simulation. Vestnik Volgogradskogo gosudarstvennogo universiteta. Seriya 4. Istoriya. Regionovedenie. Mezhdunarodnye otnosheniya [Science Journal of Volgograd State University. History. Area Studies. International Relations], 2020, vol. 25, no. 1, pp. 126-140. (in Russian). DOI: https://doi.org/10.15688/jvolsu4.2020.1.11

УДК 94:355.559

ББК 63.012
Дата поступления статьи: 13.11.2018 Дата принятия статьи: 28.01.2019

\section{НАСТОЛЬНАЯ ВОЕННО-ИСТОРИЧЕСКАЯ ИГРА КАК ФОРМА ИСТОРИЧЕСКОЙ РЕКОНСТРУКЦИИ}

\author{
Артем Игоревич Харинин \\ Волгоградский государственный университет, г. Волгоград, Российская Федерация \\ Лариса Васильевна Харинина \\ Волгоградский государственный университет, г. Волгоград, Российская Федерация
}

Аннотация. Введение. Настольные военные игры являются древним изобретением человечества. Однако в XIX в. появился новый тип военных игр, который прошел долгую эволюцию от прикладного военного пособия до исторической реконструкции, способной сыграть роль математической модели при изучении отдельных вопросов, стоящих перед исторической наукой. Meтодbl. В представленном исследовании авторы опираются на традицию «клиометрии», или «квантитативной истории». К ее методам относятся: вариатив- 
ный анализ событий, метод средних величин и статистический анализ. Анализ. В данной статье излагаются основные этапы становления настольных военно-исторических игр и показано их влияние на военное искусство и историческую науку. Рассмотрены наиболее важные трансформации - от настольных развлекательных игр к практическим штабным пособиям и далее к прикладным историческим исследованиям. Описаны принципы создания подобных игр и влияние предметной области исследования на их правила. Указаны границы применения данного метода реконструкции. Подчеркиваются преимущества и недостатки игровой реконструкции, а также ее практический потенциал в качестве вспомогательной исторической дисциплины. Дается краткий анализ основных монографий по данной проблематике. Приведены примеры военных игр, имевших важное значение в развитии метода игровой исторической реконструкции. Описаны основные современные типы настольных военных игр. Даны критерии оценки их исторической достоверности и аналитического потенциала. Результаты. Современные настольные военные игры позволяют сделать любое военно-историческое исследование более взвешенным и объективным, гибко настроить их правила под обозначенные границы предметной области исследования. Американскими исследователями изложены принципы и механизмы их создания, позволяющие самостоятельно изготовить игровую модель для тестирования определенных гипотез, выдвигаемых историком.

Ключевые слова: настольная военная игра, историческая реконструкция, соединение, зона контроля, игровой масштаб.

Цитирование. Харинин А. И., Харинина Л. В. Настольная военно-историческая игра как форма исторической реконструкции // Вестник Волгоградского государственного университета. Серия 4, История. Регионоведение. Международные отношения. - 2020. - Т. 25, № 1. - С. 126-140. - DOI: https://doi.org/10.15688/ jvolsu4.2020.1.11

Введение. Еще в глубокой древности человечеству было известно игровое моделирование событий. К его наиболее очевидным вариантам можно отнести ритуальное поражение копьями изображений животных, осуществляемое мужчинами перед охотой, разнообразные фигурки животных и людей, которые часто встречаются среди предметов детского быта и т. д. Однако в большинстве случаев такое моделирование строилось на интуитивном понимании участниками логики реконструируемых процессов. Отсутствие объективно установленных правил и соревновательного аспекта лишало игры аналитической составляющей, оставляя их в контексте детских забав или ритуальных действий.

Методы и материалы. Современная историческая наука сделала широкий шаг в сторону более глубокого и детального понимания событий прошлого. Одним из важнейших аспектов этого понимания являются попытки реконструкции исторических событий. По существу, каждый историк при изучении той или иной исторической проблемы формирует образ прошлого в своем сознании. Это, к сожалению, приводит к возрастанию субъективности и снижает научную ценность выводов. Для решения этой проблемы историческая наука прибегает к методу реконструкции объектов материальной культуры, пытаясь таким образом частично поставить себе на службу нехарактерный для нее способ эмпирической верификации. В зарубежной исторической науке в последнее время предпринимаются попытки реконструировать не только материальные объекты, но и социальное взаимодействие с помощью математического игрового моделирования.

При написании данной статьи авторы опирались на традицию «клиометрии», или «квантитативной истории», использующей количественные методы при анализе исторических событий. К числу наиболее часто применяемых методов можно отнести: вариативный анализ событий, метод средних величин и статистический анализ.

Обсуждения. В настоящее время историческая реконструкция рассматривается не только как сочетание «классической реконструкции» объектов материальной культуры и артефактов прошлого, но и как воссоздание духовной культуры, социальных отношений, мотивации и поступков исторических персонажей [2, с. 43, 375; 3, с. 239, 243]. Однако настольная военно-историческая реконструкция как метод исторического исследования сформировалась недавно. Это определило крайнюю скудность историографии по данной теме. Среди российских исследователей можно отметить только диссертацию К.В. Ябло- 


\section{ВОЙНА В ВОСПРИЯТИИ СОВРЕМЕННИКОВ И ПОТОМКОВ}

кова «Компьютерные исторические игры 1990-2000-х гг. Проблема интерпретации исторической информации» [5], которая имеет весьма опосредованное отношение к тематике данной статьи. Зарубежная историография проблемы представлена значительно шире. В качестве основоположника данного метода следует назвать Дж. Даннигана - автора монографий «The Complete Wargames Handbook» [11] и «How to Make War» [10]. Позднейшая историография связана с именами Т.Б. Аллена [7], К.Г. Левина [14], С.Д. Харринга [12] и П. Хилгерса [13], внесших значительный вклад в систематизацию практического опыта применения данного метода в прикладных исследованиях американских историков и военных специалистов. В настоящее время идет активный процесс формирования проблемного поля исследований и основных научных школ настольной военно-исторической реконструкции. Так, уже сейчас среди указанных выше авторов мы можем выделить британскую школу, в которой преобладает лично-ориентированное моделирование военных конфликтов, и американскую, стремящуюся к более глубокому применению количественных методов анализа.

Анализ. К настольным играм, обладающим достаточно сложными правилами и описывающим реальные процессы, можно отнести древнеегипетскую манкалу и древнеиндийскую чатурангу. Первая из них была посвящена земледельческим циклам и требовала от игрока понимания оптимального баланса между потребляемой частью урожая и запасами, сохраняемыми в качестве семенного фонда. Однако уже в древности осознавали, что победа может быть одержана благодаря только одним расчетам. Это превращало бы игру в обычную математическую задачу, поэтому в процесс был добавлен фактор случайности в виде жребия, определяющего урожайность тех или иных точек поля. С течением времени манкала превратилась в прототип известных нам нард, а в своих наиболее ранних вариантах сохранилась у современных народов Африки [9, p. 23].

Чатуранга была более сложной игрой, имевшей отношение к настольной реконструкции боевых действий в раннесредневековой Индии. Наиболее точное описание ее правил оставил знаменитый арабский путешественник Аль-Бируни, познакомившийся с чатурангой в Пенджабе [1, с. 27-30]. В данной игре присутствовало разделение войск по родам: собственно правитель со свитой, гвардия, слоны, кавалерия, колесницы и пехота. Использовался фактор случайности, определявший командные возможности сторон, а именно какой фигурой может ходить игрок. Однако при этом различие между фигурами состояло только в дальности и направлении доступного движения. По своим боевым возможностям все рода войск в игре были равны и гарантированно уничтожали любого противника, если могли в свой ход попасть на занятую им клетку. Действия осуществлялись игроками по очереди, и за каждый ход можно было передвинуть только одну фигуру. Таким образом, игра оставалась крайне абстрактной, плохо отражая реальные тактические особенности современных ей армий. Впоследствии развитие чатуранги и устранение из игры фактора случайности привело к появлению среднеазиатского шатранга, а позднее и современных нам шахмат.

В древности и Средневековье было изобретено множество других настольных игр, но все они жертвовали реконструктивной составляющей ради игрового азарта и интереса. По этой причине дальнейшее развитие метода игрового моделирования оказалось связанным не с эволюцией настольных игр, а с усложнением аналитической работы военных штабов Нового времени.

Штабные и командные структуры древних и средневековых армий знали использование карт как модели местности, позволявшей спланировать перемещение войск и грузов. Однако результаты боевых столкновений оставались неизвестной переменной, которую невозможно было заранее предсказать, поэтому для обозначения движений войск на карте ставили разнообразные фигурки или маркеры, не содержавшие никакой практической информации, кроме указания на конкретные воинские соединения. Командующие могли относительно адекватно реконструировать только маршевые возможности войск, но исход самого боевого столкновения оставался сложно предсказуемым. По этой причине прогностический потенциал штабного моделирования 
был достаточно слабым, и основную роль в принятии управленческих решений играла интуиция и личный опыт главнокомандующего.

Революционной попыткой предсказать результат боевого столкновения на основе детализации статистических данных стала колоссальная работа, проделанная майором прусского Генерального штаба Георгом фон Рейсвицем, которую он воплотил в 1812 г. в первой аналитической военной игре «Kriegspiel». С его игрой познакомились принцы Фридрих и Вильгельм, которым она очень понравилась, и вскоре эта забава превратилась в настоящее хобби практически всей военной элиты Пруссии. К 1824 г. «Kriegspiel» был существенно переработан сыном майора и приспособлен к массовому использованию в качестве прикладного пособия Генерального штаба по планированию операций [13, p. 57].

Представляет интерес состав игры и принцип действия «Kriegspiel». Для моделирования района боевых действий первоначально использовались сделанные из гипса квадратные элементы местности, позднее замененные на реальные топографические карты. Соединения обозначались прямоугольными брусками с характерными обозначениями конкретного рода войск на них (рис. 1). Для измерения расстояний применялись циркули, линейки и транспортиры. На каждое военное соединение составлялся особый документ, в котором указывался его численный состав, вооруженность и ряд важнейших параметров, таких как наличие продовольствия и боеприпасов, а также степень усталости личного состава. Для управления войсками имитировалась реальная иерархическая командная структура, включавшая главнокомандующего, его заместителей, ведавших различными вопросами, и командиров полевых подразделений. Противоборствующие стороны размещались в разных помещениях. Данные о передвижениях и примерном составе сил противника передавали специальные посредники, перемещавшиеся между комнатами. Такой метод позволял достаточно адекватно моделировать «туман войны» - известный эффект, сопровождающий все военные операции и заключающийся в отсутствии полноты информации о противнике. Кроме того, правило, запрещавшее устное общение между команду- ющим и его штабом с одной стороны и командирами соединений с другой, имитировало так называемое «трение Клаузевица», то есть меру недопонимания, неизбежно существующего между различными командными инстанциями и нарастающего по мере развития любой военной операции.

Самой важной особенностью «Kriegspiel» было то, что правила игры позволяли моделировать не только управление и передвижение соединений, но и сам бой. Для этого Рейсвиц отказался от услуг посредника, чей опыт и интуиция всегда несли на себе отпечаток индивидуальности и субъективности оценок. Еще во второй половине XVIII в. прусский Генштаб занимался скрупулезным сбором статистических данных обо всех известных и документально подтвержденных результатах боевых столкновений. Это позволило выявить определенные вероятности эффективности применения конкретного вида вооружения, тактических построений и влияния на них самых различных условий - от местности до степени усталости и морального состояния войск. Использование в игре данных статистики стало революционным прорывом в моделировании. Причем гениальность Георга фон Рейсвица заключалась в том, что он учел и фактор случайности. Для его имитации он использовал гауссово распределение, получавшееся при добавлении к статистическим данным, определявшим потенциальные потери противника и исход боя, результат бросков нескольких шестигранных кубиков [19, p. 53-54].

Таким образом впервые удалось осуществить синтез статического и динамического моделирования, увязав их в единый игровой континуум, имевший очень высокую степень корреляции с реальностью.

Вскоре данная модель прошла суровую проверку на практике. Еще в 1828 г. с «Kriegspiel» познакомился Гельмут Мольтке. В 1858 г. на основании опыта, полученного за игровым столом, им была создана концепция «Auftragstaktik», суть которой состояла в управлении посредством формулирования подчиненному содержания и ожидаемого позитивного результата от решения задачи. Выбор методов и способов ее решения оставался на усмотрение последнего [15, p. 33-34]. Массовое использование метода настольного игро- 


\section{ВОЙНА В ВОСПРИЯТИИ СОВРЕМЕННИКОВ И ПОТОМКОВ}

вого моделирования позволило Пруссии подготовить значительное количество офицеров, привыкших к проектному, креативному типу управления. Это стало одним из факторов победоносного окончания войн с Данией, Австрией и Францией. Особенно примечательной в этом отношении стала Франко-прусская война 1870-1871 гг., в которой в первых же приграничных сражениях обнаружилось превосходство прусского офицерского корпуса над французским, хотя первый обладал существенно меньшим практическим опытом ведения боевых действий.

Успех, который пришел к «Kriegspiel», выразился в его массовом копировании всеми передовыми государствами Европы. Вскоре появились национальные варианты правил, а несколько позднее и аналогичные военноморские игры. Так, например, в Российской империи «Kriegspiel» был издан с определенными доработками, привнесенными офицерами Генерального штаба [4, с. 7-8, 11-12]. Данная игровая модель стала повсеместно использоваться профессиональными военными как наиболее простой и дешевый способ осуществить максимально адекватное планирование или провести командно-штабные учения [21, p. 43-45]. Однако поскольку «Kriegspiel» стал прикладным пособием для профессиональных военных, то его дальнейшее развитие оказалось скованным силой уставов и традиций.

Следующий этап развития настольных военных игр как метода реконструкции оказался связан с их профанизацией и превращением в хобби для гражданских лиц.

Первую попытку адаптировать сложные правила «Kriegspiel» для широкой аудитории предпринял известный писатель Герберт Уэллс. В 1913 г. он издал свою книгу «Little Wars and Floor Games», которая представляла свод правил, позволявших воспроизвести современные той эпохе боевые действия с помощью миниатюр и изготовленной из подручных материалов местности [22, р. 69-71]. Разумеется, с точки зрения степени корреляции предложенной им модели с реальностью произошел существенный откат. Так, характеристики войск были максимально упрощены, фактор случайности играл решающую роль в определении результатов боя, отсутствовали пространственный и численный масштабы и т. д. В то же время «Little Wars and Floor Games» оказались чрезвычайно популярны у самых широких слоев населения. Это привело к появлению интереса к военным играм у писателей, предпринимателей и ученых, что послужило основанием к формированию вокруг них специфической интеллектуальной элиты, заинтересованной в их адаптации к нуждам сферы досуга, бизнеса и науки.

В 1952 г. американский отставной военный и историк Чарльз Робертс издал игру «Tactics», которая стала настоящим прорывом в сфере любительских настольных военных игр [14, p. 157]. Наиболее важным революционным изобретением, лежавшим в основе его модели, был принцип использования интегрированных данных. Прежде и «Kriegspiel», и «Little Wars and Floor Games» использовали реальные пространственный и численный масштабы, то есть все измерения в игре осуществлялись очень трудоемким образом. Так, например, для перемещения пехотного батальона на карте требовалось последовательно выполнить следующие процедуры: 1) обозначить потенциальный маршрут; 2) измерить заявленное расстояние на карте, разделяя на отрезки в зависимости от типа местности; 3) пересчитать длину полученных на карте отрезков в реальные величины; 4) свериться с табличными данными скоростей движения войск в зависимости от типа местности и указать максимально возможную дистанцию маршрута в соответствии с длительностью игрового хода, то есть, скажем, тот же пехотный батальон в рамках модели, где один ход равен одному часу, мог пройти 6 км по дороге, 4 км по открытой местности и 2 км по пересеченной. Таким образом, реальная дистанция его движения могла состоять, допустим, из 2 км дороги, 1,3 км поля и 660 м леса. Ч. Робертс предложил оригинальную и значительно более эффективную модель. Карта местности изначально была разделена на сектора, для каждого из которых определялся господствующий тип местности. Воинские соединения обладали интегрированным показателем подвижности, так называемыми очками действия, а местность - «стоимостью» пересечения одного сектора. Следовательно, расчет марша, времени, затрачиваемого на подготов- 
ку обороны, развертывание тяжелого оружия на позиции и т. п. значительно упрощались, что позволяло резко увеличить масштаб реконструируемых операций без увеличения количества игроков. Существенным допущением для измерения пространства оставались сами сектора, имевшие вид традиционной для военных карт того времени координатной сетки, то есть единицы пространства имели вид квадратов, что определяло «проблему диагонали» или неравномерной эффективности векторов движения. Однако вскоре появилась логическая игра «Гекс», одним из изобретателей которой был знаменитый математик Джон Нэш, где квадратная сетка была заменена на гексагональную, более адекватно описывающую распределение направлений движения [16, p. 34-36].

Аналогичные изменения коснулись и боевых качеств войск. Если ранее каждый параметр учитывался отдельно и требовал собственных статистических данных и вероятностных отклонений, то теперь была введена интегрированная характеристика - «боевая мощь», выражавшаяся только одним числом. Этот параметр сразу являлся производной численности, вооруженности, качества боевой подготовки и моральной устойчивости. Разумеется, для оперирования таким упрощенным значением требовались более сложные статистические данные. Однако и здесь Ч. Робертсу удалось осуществить революционную инновацию. Вместо старых таблиц, в которых указывалась зависимость потерь от силы огневого воздействия противника, была введена единая таблица боя, которая одновременно определяла и потери сторон, и победителя каждого конкретного боевого эпизода (табл. 1). Такая таблица первоначально использовала линейное распределение вероятностей, но уже со второго издания игры изменила его на гауссово. Комичным аспектом, нашедшим отражение в воспоминаниях Ч. Робертса, было то, что придуманная им таблица боя уже существовала в виде сверхсекретного проекта, разрабатывавшегося в Академии Вест-Пойнт для модернизации «Kriegspiel». Автора даже пытались привлечь к уголовной ответственности за разглашение военной тайны, но ему удалось доказать оригинальность своей концепции и выиграть дело в суде [12, p. 6].
Предельная простота данной модели позволила минимально возможному количеству человек разыграть достаточно крупные военные операции. Это предопределило невероятный коммерческий успех игры и позволило Ч. Робертсу основать собственную компанию по производству военных игр «Avalon Hill».

В 1958 г. Ч. Робертс выпустил первую игру, описывающую реальную военную операцию. Ею стал «Геттисберг», посвященный одноименному ключевому сражению 1863 г. в рамках Гражданской войны в США (рис. 2). В процессе разработки игры автору впервые пришлось иметь дело не с абстрактной военной симуляцией, а с конкретным событием прошлого во всей его уникальности. Для его корректного отображения требовалось учесть множество факторов: индивидуальные характеристики каждого военного соединения, время его появления на поле боя, цели, которые ставили перед собой командующие и т. п. Автору пришлось провести полноценное историческое исследование, в котором рассматривались наиболее важные для моделирования аспекты сражения [7, p. 15-18]. Таким образом, было положено начало настольному игровому реконструированию как методу исторического исследования.

Важную роль в разработке метода игрового моделирования сыграл Джим Данниган. На биографии этого человека следует остановиться подробнее, так как она является достаточно показательной для понимания роли и места историка и его исследований в американской науке. Первоначально он планировал сделать карьеру военного, но в 1967 г. в возрасте 24 лет, будучи специалистом по ракетному вооружению, познакомился с игрой «Ютланд», выпущенной фирмой «Avalon Hill» и посвященной одноименному морскому сражению 1916 года. Идея игровой реконструкции прошлого настолько увлекла молодого человека, что он решил полностью изменить свои жизненные планы и поступил в Университет Пейса, а затем в Колумбийский университет на факультет истории. В 1970 г. он досрочно получил степень бакалавра и выпустил игру «Panzer Blitz» (тактический симулятор боев взводного уровня периода Второй мировой войны), которая была распродана тиражом 300 тыс. экземпляров [18]. С этого момента 


\section{ВОЙНА В ВОСПРИЯТИИ СОВРЕМЕННИКОВ И ПОТОМКОВ}

он активно ведет коммерческую деятельность и основывает собственную компанию «Simulations Publications, Inc.». Параллельно с этим он пишет множество научных статей и монографий на тему настольной военно-исторической реконструкции. Показательно, что получив признание как историк, он остается высококвалифицированным военным специалистом, что позволяет ему анализировать военные конфликты прошлого максимально комплексно и глубоко.

Основные положения метода игровой реконструкции как способа исследования конфликтов прошлого он изложил в своих монографиях «The Complete Wargames Handbook» [11, p. 41-43] и «How to Make War» [10, p. 53-56].

Согласно концепции автора, целью игровой реконструкции является изучение истории не только в рамках всем известной последовательности событий, но и в контексте пространства вариантов, которые оказывали влияние на ее ход, но не получили реализации. Такой подход позволяет глубже понять мотивацию исторических личностей, а также причины многочисленных выборов, которые были ими осуществлены. Из этого следует важный методологический вывод, что сам по себе исторический процесс перестает быть детерминированной последовательностью фактов, а предстает скорее в качестве своеобразной шахматной партии, которая, конечно, уже сыграна и результат которой не может быть изменен. Однако для понимания сыгранной партии бессмысленно просто заучивать ходы, сделанные игроками. Гораздо важнее разобрать варианты, анализом которых они занимались.

Разумеется, данный метод будет эффективно работать там, где мы имеем значительное количество источников, подробно освещающих период. По этой причине настольная военная реконструкция является научным способом познания применительно к хорошо документированным конфликтам. В случае с войнами древности или Средневековья мы, скорее всего, будем иметь дело либо с симуляцией общей логики войны, либо с воспроизведением каких-то конкретных технических аспектов тактики или вооружений, способных пройти физическую проверку в рамках классической исторической реконструкции объектов материальной культуры.
Обозначив базовую цель исследования, Дж. Данниган указывает на то, что исследовательские задачи определяются предметным полем. Применительно к изучению военных конфликтов это означает, что границы игровой модели будут зависеть от того, какие аспекты конфликта мы хотим изучить. Здесь играют роль следующие показатели: 1) масштаб (тактический, оперативный, стратегический); 2) временная продолжительность (конфликт или сражение целиком или какой-либо ключевой эпизод); 3 ) роль субъективного фактора (наличие или отсутствие персонализированных характеристик у управленческих структур в игре). Чем точнее соблюдаются границы моделирования, тем корректнее будет реконструкция и тем более адекватную информацию о предмете и в конечном счете об объекте исследования мы получим. По этой причине при создании реконструктивной модели от автора требуется четкая логическая связанность выбранных масштабов пространства, времени и вооруженных сил.

После того как исследовательские задачи поставлены, необходимо переходить к объективным данным, характеризующим принцип работы реконструктивной модели.

Первым и самым важным измерением игры является пространство. В настоящее время существует несколько вариантов его моделирования: 1) карта с местностью, отображаемой макетами местности; 2) карта с гексагональной сеткой; 3 ) карта, разделенная на области; 4) карта с выделенными ключевыми населенными пунктами и коммуникациями, соединяющими их. Все эти способы имеют достаточно широкие границы применимости, но наиболее эффективно их использование по следующему алгоритму. Макетируемая местность адекватна масштабу стычки или более крупного сражения ранних периодов истории вплоть до господства линейной тактики. Гексагональная карта выступает наиболее универсальным способом структурирования пространства и хорошо работает практически во всех случаях, за некоторыми исключениями, в которых важно показать линейность боевых порядков или в которых масштаб боевого столкновения настолько мал, что определение господствующего типа местности для гексагона является недопустимым обобщением. Разделение карты 
на области или наложение на нее коммуникационной сетки с выделением узлов адекватно применяется для моделирования стратегического уровня или в случаях, когда мы испытываем недостаток адекватных данных о характере местности на театре военных действий.

В тесной связке с пространственным масштабом находится игровое время. На сегодняшний день военно-историческая реконструкция знает не только классическую схему «я хожу, ты ходишь», известную еще со времен настольных игр древности. Существует одновременный ход, действия в котором заранее записаны игроками. Ход может дробиться на фазы, в рамках которых действует только одна сторона или обе сразу. Есть также нелинейная последовательность действий, отображающая разницу в инициативе участников конфликта, когда одна сторона может последовательно осуществлять несколько действий, в то время как ее противник находится в пассивном ожидании. Выбор конкретного варианта зависит от того, какие факторы исследователю и разработчику представляются важными и принципиальными для моделирования. Однако и здесь существуют определенные принципы, заключающиеся в стремлении привязать игровую продолжительность хода к конкретной физической величине (минута, час, день, неделя и т. д.), а также в том, чтобы неизбежные паузы в ожидании игроком своего хода коррелировали с инерцией осуществления командных решений в реальном конфликте.

Определив пространственно-временной континуум игровой модели, необходимо адекватно отобразить вооруженные силы сторон конфликта. При решении этого вопроса исследователь сталкивается с рядом трудностей. Прежде всего необходимо корректно определить масштаб соединений. Их численность и уровень структурной организации должны адекватно коррелировать с пространственно-временным континуумом. Приведем пример. Допустим, мы стремимся моделировать боевые действия периода Второй мировой войны на мелкотактическом уровне. В таком случае в качестве структурной единицы пространства нами выбран гексагон с расстоянием, между противоположными сторонами равным 50 реальным метрам, а один игровой ход равен 5 ми- нутам. Очевидно, что корректный выбор организационного масштаба военного соединения будет связан с отделениями и отдельными единицами тяжелого оружия. Это прямо вытекает как из уставных плотностей войск, так и из известной нам по документам практики их боевого применения. Использование более крупных подразделений, например рот, создаст проблему появления пробелов, не заполненных войсками при формировании диспозиции, хотя чисто физически 100-200 человек вполне мо-

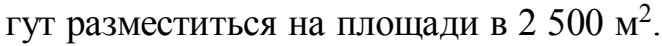

При определении масштабов воинских соединений необходимо гибко подходить к официально заявленной в документах эпохи структурной номенклатуре. Так, например, в годы той же Второй мировой войны дивизии разных стран имели достаточно сильно различавшийся численный масштаб и вооруженность. Создание игровых фишек исключительно дивизионного уровня для моделирования какой-либо операции может оказаться некорректным. По этой причине необходимо руководствоваться минимально возможной плотностью войск применительно к боевым порядкам эпохи. Для отражения возможностей по концентрации значительных сил на узком направлении используется принцип «лимита стекования», то есть максимального количества сил, способных находится в одной структурной единице пространства.

Более сложным вопросом при моделировании воинских частей выступает проблема установления статистического эквивалента их боевых возможностей. Существует несколько способов решения этой задачи.

Первым и наиболее распространенным является поиск интегрированного значения, зависящего, прежде всего, от численности, вооруженности и качества подготовки соединения. В монографии «The Complete Wargames Handbook» Дж. Данниган приводит пример собственной методики. Она строится по следующему алгоритму. На первом этапе, как говорит автор, необходимо найти «боевой квант». Под этим он подразумевает самое малочисленное, слабовооруженное и неподготовленное подразделение в реконструируемом конфликте, которое находится на один уровень ниже выбранного нами масштаба подразделений. Поясним эту мысль. Допустим, нам необходимо воспроиз- 


\section{ВОЙНА В ВОСПРИЯТИИ СОВРЕМЕННИКОВ И ПОТОМКОВ}

вести Бородинскую битву. При этом решено, что оптимальным масштабом соединений, в соответствии с нашими исследовательскими задачами, будут пехотные дивизии. Следовательно, требуется найти среди них самую слабую. Мы принимаем эту часть за $100 \%$. После этого сравниваем с ней все прочие соединения и определяем, на сколько процентов они будут эффективнее. При этом мы интегрируем в единое целое их численность, вооруженность и подготовку на основании эмпирических данных, имеющихся в исторических источниках. В итоге получаем числа превышающие $100 \%$, например $120 \%, 146$ \% и т. д. Финальной процедурой является пропорциональноеуменьшение числа до минимально возможного целого значения [11, p. 17-18]. Если речь идет о конфликтах Новейшего времени и современности, используются интегрированные таблицы мощи, позволяющие быстро и эффективно определять боевую мощь подразделения. Классическим примером подобного является «Infantry Fire Table» (табл. 2), используемая в очень популярном тактическом симуляторе «Advanced Squad Leader» [6].

Вторым вариантом определения характеристик боевых частей является выделение нескольких ключевых параметров и раздельная оценка каждого из них по определенной шкале эффективности. Последняя зависит от максимально возможной эффективности конкретного свойства в рамках реконструируемого исторического периода. Поясним. Допустим, нашей задачей является построение модели эффективности противотанковых средств с помощью гауссова распределения, формируемого броском двух шестигранных кубиков. В зависимости от временного периода мы получаем несколько моделей, отличающихся минимальным шагом изменения характеристик. Так, если речь идет о периоде Второй мировой войны, то в рамках 11 различных значений, получающихся от суммы бросков двух шестигранников, у нас помещается разлет характеристик бронирования от 10-15 мм до 200-240 мм. А если мы используем тот же статистический инструментарий, но применительно к современным конфликтам, то в те же 11 значений необходимо поместить более широкий диапазон значений - от 15-30 мм до примерно 1000 мм (с учетом современной композитной и многоуровневой броневой защиты). Сочетать в рамках одной игры две столь различные модели некорректно. Таким образом, базовым постулатом второго принципа формирования характеристик боевых частей является сравнение их не друг с другом, а с неким идеальным результатом, определяемым объективными материальными возможностями изучаемого исторического периода.

Указанные выше подходы к установлению боевых характеристик в значительной степени зависят от выбранного исследователем масштаба. Первый вариант в большей степени тяготеет к оперативному и стратегическому уровню реконструкции, второй - к тактическому.

Следующим шагом построения игровой модели является определение целей сторон. Эта задача, как правило, представляется достаточно простой, так как адекватное указание победных условий для каждой из сторон конфликта детерминировано конечным результатом сражения, военной операции или конфликта, известным и хорошо изученным благодаря военно-исторической литературе. Однако такой подход обнаруживает некоторую поверхностность при моделировании боевых действий. В реальности, в отличие от шахмат и иных абстрактных настольных игр, силы сторон почти никогда не являются равными и симметричными. Исходя из этого, степень эффективности стороны конфликта не может быть сведена к простой оценке - победила ли она или проиграла. Напротив, многие формальные поражения в конкретных битвах или операциях, в зависимости от последовавших за этим изменений в общем стратегическом балансе, могли привести к прямо противоположному результату. Классическим примером подобного является битва при Березине 1812 г., которая отечественной историографией однозначно трактуется как победа над Наполеоном. В иностранной военно-исторической литературе, напротив, она рассматривается как пример эффективного сохранения важнейших кадров армии в практически безнадежной ситуации $[17$, p. 72$]$. Строго говоря, то, что Наполеону удалось вырваться из окружения и спасти свой генералитет и значительную часть офицерского корпуса, привело к крайне неоднозначному началу кампании 1813 г. и пора- 
жениям при Бауцене и Люцене. Только вступление в 6-ю антифранцузскую коалицию Австрии предопределило победу в генеральном сражении у Лейпцига и перелом в войне.

Таким образом, при моделировании целей игровой реконструкции исследователь должен отказаться от влияния, оказываемого на него знанием о конечных результатах, и, соблюдая принцип историзма, максимально тщательно изучить планы сторон, синхронные началу рассматриваемого военного эпизода. Подобный анализ приводит к парадоксальному выводу: несмотря на то что военные действия являются одной из высших форм противостояния, цели, которые стороны ставят перед собой, могут не противоречить друг другу и иногда даже совпадать. Именно по этой причине наиболее адекватной моделью оценки результатов, достигнутых участниками конфликта, является так называемая система «победных очков». Суть этой системы заключается в выделении максимального количества задач, решение которых предполагал реальный военный план, и присвоении каждой из них определенного количества баллов в зависимости от ее значимости. При окончании игры стороны сравнивают заработанные ими победные очки и определяют того, кто был ближе к реализации военных планов. Такая система присутствует в большинстве современных настольных военных игр.

Другой подход заключается в еще более вариативном отношении к военному планированию и предоставляет игрокам самим выбирать план и формулируемые им цели и задачи из нескольких вариантов, которые обсуждались в реальных командных инстанциях еще до принятия решения о начале боевого столкновения. Интересным примером подобного подхода является игра «Bulge 20: The Ardennes Offensive» [8], посвященная реконструкции немецкого наступления в Арденнах в конце 1944 года. В ней оба игрока имеют возможность выбора между несколькими планами операции, которые определяют победные условия, организационно-штатную структуру наличных сил («order of battle»), а также направленность и интенсивность работы тыловых коммуникаций.

После осуществления всех указанных выше процедур мы получаем реконструктив- ную модель битвы, операции или войны в целом. При условии соблюдения изложенных принципов степень корреляции модели с реальностью будет достаточно высокой. Однако существует одна переменная, которая очень плохо поддается реконструированию, это субъективный фактор, заключающийся во влиянии личности командующего и составленного им плана действий, что особенно ярко проявляется в случае совершения им однозначной ошибки и, как следствие, поражения от более слабого противника. В качестве примера подобного можно привести сражение при Аустерлице 1805 г., когда более многочисленная и находящаяся на сильной позиции союзная армия в силу ошибочного наступления, предпринятого на своем левом фланге, оказалась разгромлена меньшей по силе французской армией. Очевидно, что при реконструкции подобной битвы ни один знающий историю игрок не повторит действий русско-австрийского командования. Следовательно, в рамках классической модели настольного военного реконструирования такие битвы принципиально не могут быть предметом исследования, так как их ход обусловлен очевидными ошибками, не нуждающимися в анализе вариантов. Разумеется, существует множество способов ввести в игровую модель специальные правила, позволяющие сделать реконструкцию таких битв интересной. Во-первых, это наличие предписанных планом первичных действий, от которых не может отказаться игрок и которые заставляют его искать спасительные решения в кульминационный момент сражения. Вовторых, это ограничения, распространяющиеся на тактические особенности игровых боевых частей, определяемые спецификой тактики или воинских традиций. Так, например, в игре «Shako» [20], посвященной периоду наполеоновских войн, лучший уровень подготовки кадров во французской армии нашел выражение в способности ее частей немедленно осуществлять развертывание из колонны в линию и обратно, не затрачивая на это игрового хода. Так или иначе, данные изменения не позволяют уйти от проблемы уникальности каждого конкретного события истории и существенно снижают реконструктивный потенциал настольной игры. 


\section{ВОЙНА В ВОСПРИЯТИИ СОВРЕМЕННИКОВ И ПОТОМКОВ}

Результаты. Завершая анализ метода исторической реконструкции с помощью настольных военных игр, необходимо сделать следующие наиболее значимые выводы.

Современные настольные военные игры, выросшие из командно-штабных игр XIX$\mathrm{XX}$ вв., отличаются очень качественными математическими моделями, позволяющими учитывать массу объективных факторов, играющих важную роль в боевых действиях. Учет этих данных позволяет сделать любое военноисторическое исследование более взвешенным и менее личностно ангажированным.

Настольные военные игры обладают высоким адаптационным потенциалом, позволяющим гибко настраивать их правила под обозначенные границы предметной области исследования. Американскими исследователями изложены принципы и механизмы их создания, с помощью которых можно самостоятельно изготовить игровую модель для тестирования определенных гипотез, выдвигаемых историком.

Ключевым ограничением данного метода является анализ субъективных данных роли личности в истории, моральных свойств войск и т. п. По этой причине оптимальным предметом исследования служат войны и конфликты с устоявшимися тактическими приемами без участия гениальных или бездарных командующих. Это определяет особую эффективность метода при исследовании конфликтов XX в., в которых господствовал принцип коллегиального управления. 


\section{ПРИЛОЖЕНИЕ}

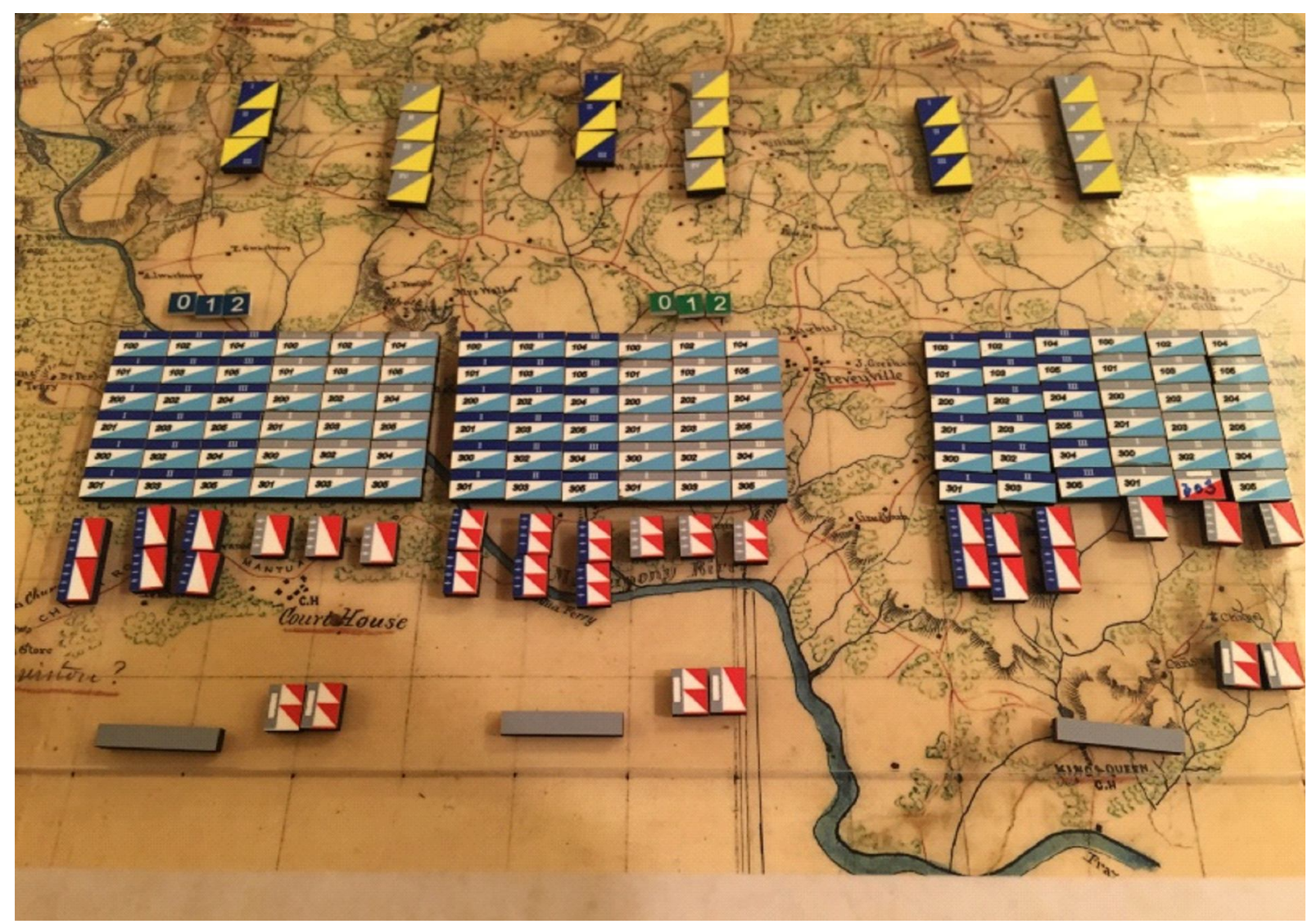

Рис. 1. «Kriegspiel». Компоненты игры

Fig. 1. "Kriegspiel". Game components

Таблииа 1. Таблица результатов боя. Настольная военная игра «Tactics»

Table 1. Combat Result Table. "Tactics" Wargame

\begin{tabular}{|c|c|c|c|c|c|c|c|c|}
\hline Die roll & $1-3$ & $1-2$ & $1-1$ & $3-2$ & $2-1$ & $3-1$ & $4-1$ & $5-1$ \\
\hline- & $\mathrm{AE}$ & $\mathrm{AE}$ & $\mathrm{AE}$ & $3 /-$ & $3 /-$ & $2 /-$ & $2 /-$ & $1 /-$ \\
\hline 1 & $\mathrm{AE}$ & $\mathrm{AE}$ & $3 /-$ & $3 /-$ & $2 /-$ & $2 /-$ & $1 /-$ & $1 /-$ \\
\hline 2 & $\mathrm{AE}$ & $3 /-$ & $3 /-$ & $2 /-$ & $2 /-$ & $1 /-$ & $1 /-$ & {$[-/ 1]$} \\
\hline 3 & $3 /-$ & $3 /-$ & $2 /-$ & $2 /-$ & $1 /-$ & $1 /-$ & {$[-/ 1]$} & $-/ 2^{*}$ \\
\hline 4 & $3 /-$ & $2 /-$ & $2 /-$ & $1 /-$ & $1 /-$ & {$[-/ 1]$} & $-/ 2^{*}$ & $-/ 3^{*}$ \\
\hline 5 & $2 /-$ & $2 /-$ & $1 /-$ & $1 /-$ & {$[-/ 1]$} & $-/ 2^{*}$ & $-/ 3^{*}$ & $\mathrm{DE}$ \\
\hline 6 & $2 /-$ & $1 /-$ & $1 /-$ & {$[-/ 1]$} & $-/ 2^{*}$ & $-/ 3^{*}$ & $\mathrm{DE}$ & $\mathrm{DE}$ \\
\hline 7 & $1 /-$ & $1 /-$ & {$[-/ 1]$} & $-/ 2^{*}$ & $-/ 3^{*}$ & $\mathrm{DE}$ & $\mathrm{DE}$ & $\mathrm{DE}$ \\
\hline 8 & $1 /-$ & {$[-/ 1]$} & $-/ 2$ & $-/ 3^{*}$ & $\mathrm{DE}$ & $\mathrm{DE}$ & $\mathrm{DE}$ & $\mathrm{DE}$ \\
\hline+ & {$[-/ 1]$} & $-/ 2$ & $-/ 3$ & $\mathrm{DE}$ & $\mathrm{DE}$ & $\mathrm{DE}$ & $\mathrm{DE}$ & $\mathrm{DE}$ \\
\hline
\end{tabular}




\section{ВОЙНА В ВОСПРИЯТИИ СОВРЕМЕННИКОВ И ПОТОМКОВ}

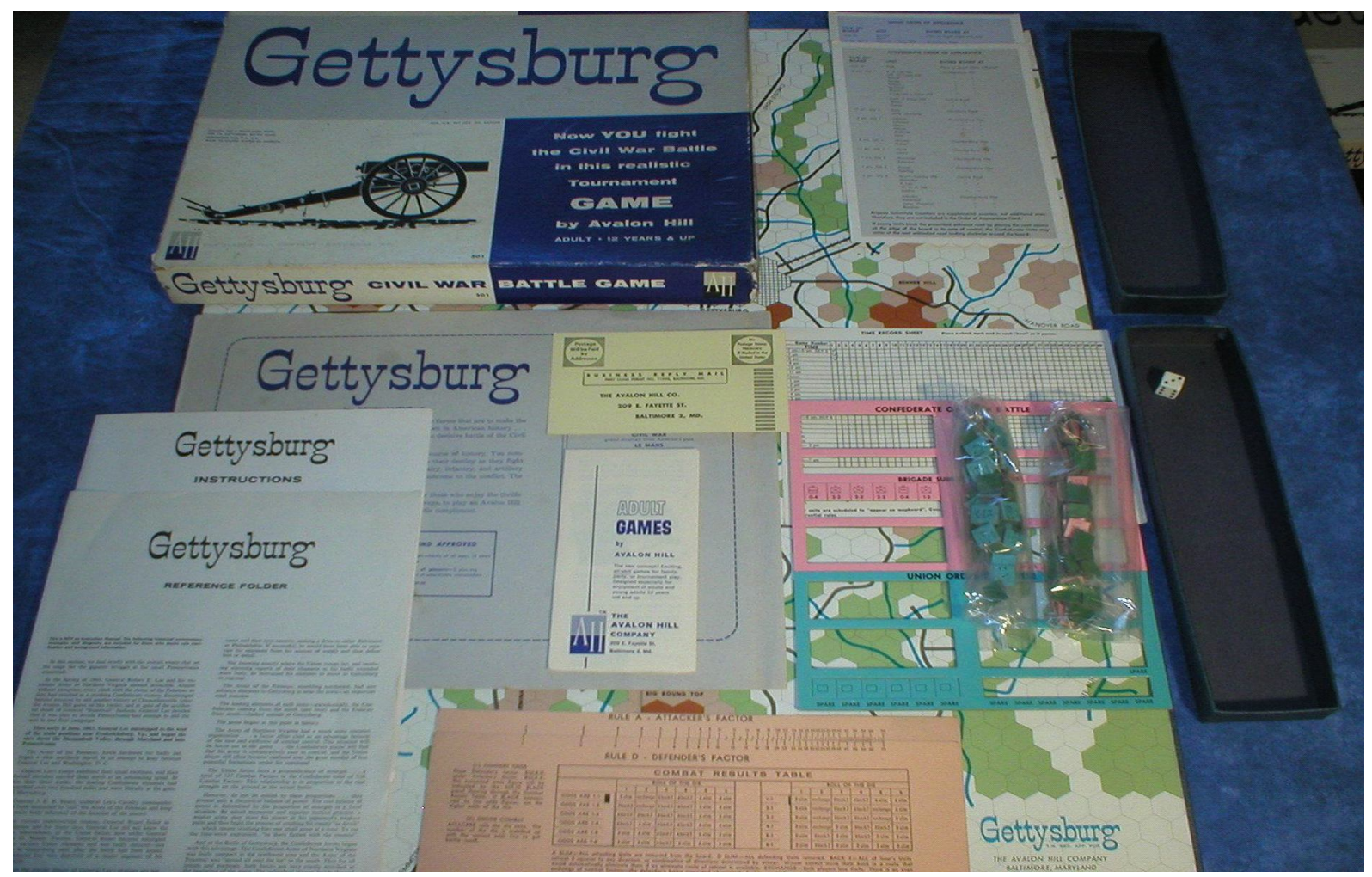

Рис. 2. Настольная военная игра «Геттисберг» 1958 года. Компоненты игры

Fig. 2. "Gettysberg" Wargame of 1958. Game components

Таблица 2. Таблица пехотного огня. Настольная военная игра «Advanced Squad Leader» Table 2. Infantry fire table. "Advanced Squad Leader" Wargame

\begin{tabular}{|c|c|c|c|c|c|c|}
\hline \multicolumn{10}{|c|}{ A7 INFANTRY FIRE TABLE (IFT) } \\
\multicolumn{8}{|c|}{ PFk } \\
Backblast \\
dr
\end{tabular}




\section{СПИСОК ЛИТЕРАТУРЫ}

1. Бируни, А. Р. Индия / А. Р. Бируни. - М. : Ладомир, 1995. - 727 с.

2. Ильичев, Л. Ф. Методологические проблемы общественных наук / Л. Ф. Ильичев. - М. : Наука, 1979. $-472 \mathrm{c}$.

3. Ковальченко, И. Д. Методы исторического исследования / И. Д. Ковальченко. - М. : Наука, 2003. $-485 \mathrm{c}$.

4. Кузминский, А. Руководство къ военной игръ / А. Кузминский. -2-е изд. - Спб. : Воен. тип., 1848. $-221 \mathrm{c}$

5. Яблоков, К. В. Компьютерные исторические игры 1990-2000-х гг. : Проблемы интерпретации исторической информации : дис. ... канд. ист. наук / Яблоков Кирилл Валерьевич. - М., 2005. $252 \mathrm{c}$.

6. Advanced Squad Leader // Board Game Geek. - Electronic text data. - Mode of access: https:// boardgamegeek.com/boardgame/243/advancedsquad-leader. - Title from screen.

7. Allen, T. B. War Games / T. B. Allen. Berkeley : The Universitet of California Press, 1989.$402 \mathrm{p}$.

8. Bulge 20: The Ardennes Offensive // Victoru Point Games. - Electronic text data. - Mode of access: https://victorypointgames.com/documents/B20 notes.pdf. - Title from screen.

9. Crane, L. African Games of Strategy: ATeaching Manual / L. Crane. - Urbana : University of Illinois Press, $1982 .-53 \mathrm{p}$

10. Dunnigan, J. F. How to Make War: A Comprehensive Guide to Modern Warfare in the Twenty-first Century/ J. F. Dunnigan. - N. Y. : Harper Collins, 2003. $-672 \mathrm{p}$.

11. Dunnigan, J. F. The Complete Wargames Handbook: How to Play and Design Commercial and Professional Wargames / J. F. Dunnigan. Bloomington : in Universe, 2000. -417 p.

12. Harring, S. D. Second Sight: The Millennium's Best "Other" Game and the Millennium's Most Influential Person / S. D. Harring // Pyramid. - 1999. Dec. 24. - P. 3-15.

13. Hilgers, P. War Games: A History of War on Paper / P. Hilgers. - L. : MIT Press, 2012. - 240 p.

14. Lewin, C. G. War Games and Their History / C. G. Lewin. - N. Y. : Fonthill Media, 2012. - 272 p.

15. MacNab, I. Kriegspiel and the Sandtable: Using Tabletop Waargames to Teach Tactics and Exercise Decision Making in the Classroom / I. MacNab. - West Point : US military Academy, 2012. - 174 p.

16. Mathematical Games: Hex, Tic-Tac-Toe, Solved Game, Sprouts, Pentomino, Phutball, Nim, Dots and Boxes, Tangloid, Tactix. - Memphis : General Books, 2010. - 206 p.
17. Mikaberidze, A. The Battle of Berezina: Napoleon's Great Escape / A. Mikaberidze. - Barnsley : Pen and Sword Military, 2010. - 284 p.

18. Panzer Blitz // Board Game Geek. - Electronic text data. - Mode of access: https://www.boardgamegeek. com/boardgame/2238/panzerblitz. - Title from screen.

19. Reisswitz, B. Von. Kriegspiel : Instructions for Representation of Military Manoeuvres with the Kriegspiel Apparatus / B. Von Reisswtz. - Stanford : B. Leeson, 1983. - 123 p.

20. Shako // Board Game Geek. - Electronic text data. - Mode of access: https://boardgamegeek.com/ boardgame/22186/shako. - Title from screen.

21. Verdy's Free Kriegspiel including the Victorian Army’s 1896 War Game / ed. by J. Curry. - L. : Lulu Publ., 2008. - 163 p.

22. Wells, H. Little Wars and Floor Games / H. Wells. - N. Y. : Dover Publications, 2015. - 182 p.

\section{REFERENCES}

1. Biruni A.R. Indiya [India]. Moscow, Ladomir Publ., 1995. 727 p.

2. Ilyichev L.F. Metodologicheskie problemy obshchestvennykh nauk [Methodological Problems of Social Sciences]. Moscow, Nauka Publ., 1979. 472 p.

3. Kovalchenko I.D. Metody istoricheskogo issledovaniya [Methods of Historical Research]. Moscow, Nauka Publ., 2003. 485 p.

4. Kuzminskiy A. Rukovodstvo $k$ voennoy igre [Guide to the Wargame]. Saint Petersburg, Voennaya tipografiya, $1848.221 \mathrm{p}$.

5. Yablokov K.V. Kompyuternye istoricheskie igry 1990-2000-kh gg.: Problemy interpretatsii istoricheskoy informatsii: dis. ... kand. ist. nauk [Computer Historical Games of the 1990s - 2000s: Problems of Interpretation of Historical Information. Cand. hist. sci. diss.]. Moscow, 2005. 252 p.

6. Advanced Squad Leader. Board Game Geek. URL: https://boardgamegeek.com/boardgame/243/ advanced-squad-leader.

7. Allen T.B. War Games. Berkeley, The Universitet of California Press, 1989. 402 p.

8. Bulge 20: The Ardennes Offensive. Victoru Point Games. URL: https:/victorypointgames.com/ documents/B20_notes.pdf.

9. Crane L. African Games of Strategy: A Teaching Manual. Urbana, University of Illinois Press, 1982. $53 \mathrm{p}$.

10. Dunnigan J.F. How to Make War: A Comprehensive Guide to Modern Warfare in the Twenty-First Century. New York, Harper Collins, 2003. $672 \mathrm{p}$.

11. Dunnigan J.F. The Complete Wargames Handbook: How to Play and Design Commercial and 


\section{ВОЙНА В ВОСПРИЯТИИ СОВРЕМЕННИКОВ И ПОТОМКОВ}

Professional Wargames. Bloomington, Universe, 2000. $417 \mathrm{p}$.

12. Harring S.D. Second Sight: The Millennium's Best “Other" Game and the Millennium's Most Influential Person. Pyramid, 1999, December 24, pp. 3-15.

13. Hilgers P. War Games: A History of War on Paper. London, MIT Press, 2012. 240 p.

14. Lewin C.G. War Games and Their History. New York, Fonthill Media, 2012. 272 p.

15. MacNab I. Kriegspiel and the Sandtable: Using Tabletop Wargames to Teach Tactics and Exercise Decision Making in the Classroom. West Point, US military Academy, 2012. 174 p.

16. Mathematical Games: Hex, Tic-Tac-Toe, Solved Game, Sprouts, Pentomino, Phutball, Nim, Dots and Boxes, Tangloid, Tactix. Memphis, General Books, 2010. 206 p.
17. Mikaberidze A. The Battle of Berezina: Napoleon's Great Escape. Barnsley, Pen and Sword Military, 2010. 284 p.

18. Panzer Blitz. Board Game Geek. URL: https:// www.boardgamegeek.com/boardgame/2238/ panzerblitz.

19. Reisswitz B. Von. Kriegspiel: Instructions for Representation of Military Manoeuvres with the Kriegspiel Apparatus. Stanford, B. Leeson, 1983. $123 \mathrm{p}$.

20. Shako. Board Game Geek. URL: https:// boardgamegeek.com/boardgame/22186/shako.

21. Curry J., ed. Verdy's Free Kriegspiel Including the Victorian Army's 1896 War Game. London, Lulu Publications, 2008. 163 p.

22. Wells H. Little Wars and Floor Games. New York, Dover Publications, 2015. 182 p.

\section{Information About the Authors}

Artem I. Kharinin, Candidate of Sciences (History), Senior Lecturer, Department of Social Technology, Volgograd State University, Prosp. Universitetsky, 100, 400062 Volgograd, Russian Federation, kharinin@volsu.ru, https://orcid.org/0000-0002-5414-2747

Larisa V. Kharinina, Candidate of Sciences (History), Associate Professor, Department of Sociology and Social Technology, Volgograd State University, Prosp. Universitetsky, 100, 400062 Volgograd, Russian Federation, kharinina@volsu.ru, https://orcid.org/0000-0001-9350-941X

\section{Информация об авторах}

Артем Игоревич Харинин, кандидат исторических наук, старший преподаватель кафедры социологии и социальных технологий, Волгоградский государственный университет, просп. Университетский, 100, 400062 г. Волгоград, Российская Федерация, kharinin@volsu.ru, https://orcid.org/0000-0002-5414-2747

Лариса Васильевна Харинина, кандидат исторических наук, доцент кафедры социологии и социальных технологий, Волгоградский государственный университет, просп. Университетский, 100, 400062 г. Волгоград, Российская Федерация, kharinina@volsu.ru, https://orcid.org/0000-0001-9350-941X 